Lilis Suryani, Salmah Orbayinah

1,2Prodi M ikrobiologi dan Biokimia, Fakultas K edokteran dan IImu

K esehatan,

U niversitas M uhammadiyah

Yogyakarta

Jalan B rawijaya, Tamantirto, K asihan,

Bantul, Yogyakarta 55183

1E mail: lilis.suryani@umy.ac.id

\section{Upaya Preventif Penyakit Water Borne Disease Pada Masyarakat Paska Gempa Bumi Yogyakarta}

\author{
https:/ / doi.org/ 10.18196/ bdr.5228
}

\begin{abstract}
ABSTRAK
Gempa bumi besar yang terjadi di Yogyakarta menyebabkan sebagian besar sumur warga mengalami kerusakan. Sumur mengalami pendangkalan, air menjadi keruh, saluran air dari septitank banyak yang pecah. Hal ini menimbulkan masalah bagi kesehatan karena banyak air sumur yang tak layak untuk dikonsumsi. Air bersih merupakan kebutuhan pokok masyarakat Indonesia. Air bersih harus memenuhi persyaratan baik fisik, mikrobiologis dan kimiawi. Air yang tidak memenuhi persyaratan bisa menjadi media penularan berbagai penyakit saluran pencernaan (Water borne disease). Penyakit saluran pencernaan sangat berhubungan dengan perilaku manusia, sarana air bersih, pembuangan limbah dan kesehatan lingkungan. Salah satu upaya pencegahan penyakit water borne disease adalah mengetahui kelayakan sumber air minum di daerah terdampak gempa. Pengabdian pada masyarakat ini dilakukan di salah satu desa terdampak gempa yaitu Trirenggo, Bantul, Provinsi DIY. Kegiatan pengabdian pada masyarakat ini dilakukan dalam rangka untuk meningkatkan pemahaman masyarakat terdampak gempa tentang pentingnya penyediaan air berkualitas yang memenuhi syarat kesehatan. Pelaksanaan kegiatan ada dua tahap yakni penyuluhan dan pemeriksaan. Penyuluhan dalam bentuk sosialisasi usaha promotif dan preventif manfaat air bersih bagi kesehatan dalam bentuk penyuluhan yang dilaksanakan di Balai Pertemuan Dusun Pepe, Desa Trirenggo, Bantul. Penduduk yang datang dalam penyuluhan lebih kurang 100 kepala keluarga. Peserta yang datang meliputi para pengurus desa, para kader kesehatan, ketua karang taruna serta ibu-ibu di sekitar yang mempunyai sumur sendiri yang mengalami kerusakan akibat gempa bumi. Pemeriksaan kualitas air dilakukan di laboratorium Mikrobiologi FKIK UMY untuk menguji kualitas mikrobiologik dan LABDA Provinsi DI Yogyakarta untuk menguji kesadahan air. Dari sekitar 150 sumber air minum, secara acak diambil 100 sampel air sumur. Hasil pemeriksaan kualitas air di Desa Trirenggo menunjukkan bahwa 97 \% sumur penduduk positif terkontaminasi bakteri Escherichia coli. Hasil pemeriksaan kesadahan air sumur masih dalam ambang batas normal. Air sumur gali di desa Trirenggo Bantul hanya 3\% yang layak memenuhi standar baku kualitas air. Peningkatan pemahaman pengetahuan masyarakat akan pentingnya air bersih akan mempengaruhi perilaku dalam pencegahan penyakit water borne disease.
\end{abstract}

Kata Kunci: Kualitas, Sumber Air minum, Masyarakat, Paska Gempa

\title{
PENDAHULUAN
}

Bencana gempa bumi menimbulkan banyak kerugian pada masyarakat, selain korban meninggal dunia, kurban luka berat, juga kerusakan fasilitasumum seperti jalan, saluran 


\section{1}

air dan saluran pembuangan limbah. K asus penyakit menular makin meningkat seiring dengan makin berkurangnya pasokan air bersih dan sanitasi lingkungan yang memburuk (Pan A merican H ealth O rganization, 2006). Dampak gempa di Provinsi D I Yogyakarta tahun 2006, menyebabkan kurban meninggal dunia berjumlah 4143 jiwa, kurban luka berat 12026 jiwa, fasilitas kesehatan yang rusak sebesar 94 buah dan rumah penduduk rusak berat berjumlah 78622 .

Salah satu akibat rusaknya fasilitas umum dan kesehatan adalah munculnya kejadian luar biasa (KLB) diare dan disentri yang dipengaruhi oleh ketersediaan sumber air minum yang sangat terbatas. Sanitasi lingkungan sebagai kebutuhan penting di awal timbulnya bencana (The Sphere Project, 2011; Tekeli-Yesil, 2006). KLB di daerah bencana gempa bumi sering terjadi akibat kon disi lingkungan yang kurang higienis, persediaan air terbatas serta jumlah jamban atau fasilitas mandi cuci kakus (M CK) sangat terbatas.

Sejak terjadi gempa, sebagian besar sumur milik warga di D aerah Istimewa Yogyakarta banyak yang rusak, terjadi pendangkalan, air menjadi keruh bahkan ada yang sama sekali tak keluar air karena tanah dasar sumur naik. Banyak air sumur yang tak layak untuk dikonsumsi. Namun karena kebutuhan air mendesak, sementara bantuan yang datang melalui bak di posko dusun tak bisa rutin, warga terpaksa mengambil air sumur setelah dilakukan pengerukan atau pengeboran secara swadaya. Banyaknya rumah dan tempat penampungan limbah yang rusak, dikhawatirkan menimbulkan pencemaran lingkungan. Sebab pada musim penghujan, limbah di tempat penampungan akan mencemari mata air yang ada di dekatnya. Pada musim penghujan, limbah yang ada di penampungan akan mengalir dan mencemari sumber-sumber mata air yang ada di dekatnya. Jika hal itu terjadi dikhawatirkan bisa menyebabkan penyakit seperti diare.

D esa Trirenggo, Kecamatan Bantul, Kabupaten Bantul terletak kurang lebih $12 \mathrm{~km}$ dari pusat kota Yogyakarta. Secara geografis, Kabupaten Bantul terletak antara 07여'04" -0800'27" Lintang Selatan dan 11012'34" - 11031'08" Bujur Timur. Di sebelah timur berbatasan dengan Kabupaten Gunungkidul, di sebelah utara berbatasan dengan Kota Yogyakarta dan Kabupaten Sleman, di sebelah barat berbatasan dengan Kabupaten Kulon Progo, dan di sebelah selatan berbatasan dengan Samudra Indonesia. U ntuk memgetahui sejauh mana tingkat kerusakan sumber air minum (sumur) di daerah Trirenggo Bantul maka pengabdian masyarakat ini penting dilakukan di daerah tersebut. Sebagai upaya untuk mengetahui kelayakan sumber air minum di daerah tersebut. D engan mengetahui kondisi sumur di daerah Trirenggo maka usaha pencegahan penyakit menular lewat air (water borne disease) yang disebabkan karena sumber air minum yang tidak memenuhi 
syarat untuk dikonsumsi dapat ditanggulangi sedini mungkin. Pengabdian kepada masyarakat ini bertujuan untuk meningkatkan wawasan dan pengetahuan penduduk desa Trirenggo, kecamatan Bantul, kabupaten Bantul, Yogyakarta tentang manfaat air bersih bagi kesehatan dan pencegahan penyakit menular lewat air (Water borne disease) serta mengadakan pemeriksaan fisik, kimia, dan bakteriologi pada sumber air minum penduduk untuk mengetahui kualitas sumber air tersebut pasca gempa bumi.

\section{METODE PELAKSANAAN}

Pada kegiatan pengabdian pada masyarakat ini, metode yang digunakan untuk mengungkapkan proses peningkatan pemahaman masyarakat melalui penyuluhan, analisis kualitas air (pengambilan sampel air bersama masyarakat, uji laboratorium), serta Focus $G$ roup D iscussion (FGD) tentang hasil uji kualitas air dan tanggapan atau persepsi masyarakat.

1) Peningkatan pemahaman masyarakatmelalui sosialisasi dalam bentuk

penyuluhan dengan judul "Manfaat Air Bersih Bagi Kesehatan"

Sebagai langkah awal untuk memberi motivasi dan menyadarkan masyarakat akan pentingnya penyediaan air bersih bagi kesehatan tubuh dilakukan dengan sosialisasi. Pelaksanaan sosialisasi usaha promotif dan preventif dalam bentuk penyuluhan kesehatan lingkungan dilaksanakan di Balai Pertemuan Dusun Pepe, Desa Trirenggo, Bantul. Penduduk yang hadir dalam penyuluhan lebih kurang 100 kepala keluarga. Peserta yang datang meliputi para pengurus desa, para kader kesehatan, ketua karang taruna serta ibu-ibu di sekitar yang mempunyai sumur sen diri yang mengalami kerusakan akibat gempa bumi. Kegiatan diawali dengan membagikan pretes dalam bentuk kuesioner yang berisi tentang manfaat air, syarat air bersih, dan penyakit saluran pencernaan yang ditularkan melalui air untuk semua peserta yang hadir. Pretes dilakukan untuk mengetahui tingkat pengetahuan peserta tentang manfaat air bersih, kriteria air yang berkualitas dan penyakit yang disebarkan melalui air. Kegiatan dilanjutkan dengan ceramah, pembagian leaflet dan diakhiri tanya jawab yang berkaitan dengan pemanfaatan air bersih.

2) Pemeriksaan kualitas air yang diambil dari sumur peserta pengabdian

Pemeriksaan kualitas air dilakukan dengan cara mengambil sampel air dari sumur penduduk secara aseptik. Total sampel air yang diambil ada 100 sumber, teknik pengambilan dilakukan secara acak. Volume air yang digunakan sebesar $100 \mathrm{ml}$ menggunakan botol steril. Sampel air selanjutnya dibawa ke laboratorium M ikrobiologi 
FKIK U MY untuk dilakukan pemeriksaan kualitas mikrobiologis dengan metode M ost Probable Number (MPN) dan sebagian dikirim ke Laboratorium Balai Teknologi Kesehatan Lingkungan (BTKL) Provinsi DI Yogyakarta untuk diperiksa kadar kalsium dan magnesium. Teknik pengambilan sampel air dan cara pemeriksaannya dapat dilihat pada Gambar 2.
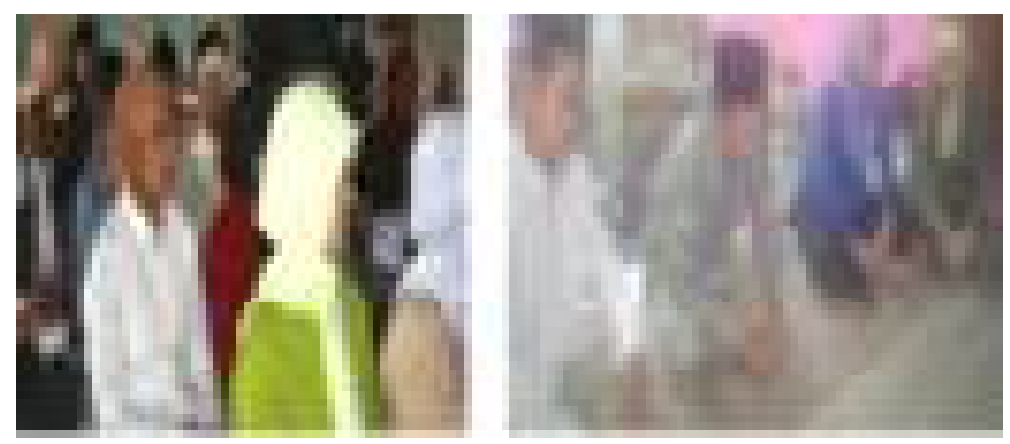

Gambar 1. Kegiatan sosialisasi penyuluhan dan pemaparan hasil pemeriksaan kualitas air sumur di Desa Trirenggo Bantul
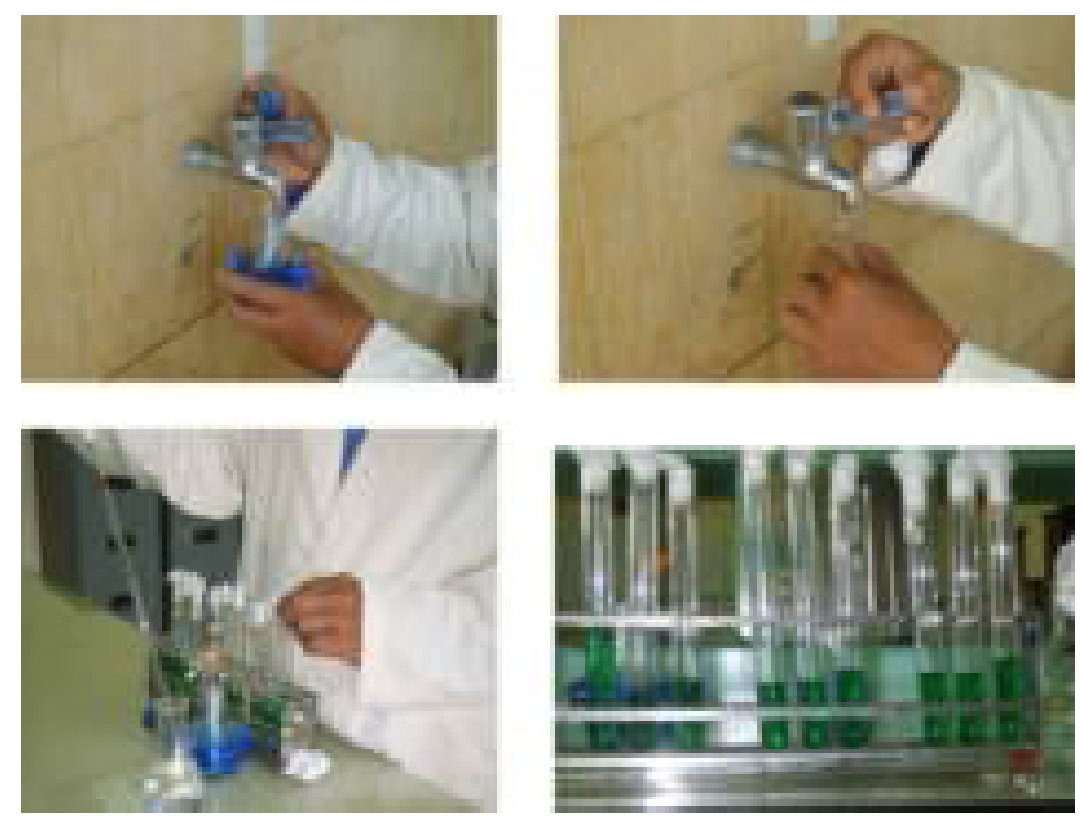

Gambar 2. Teknik pengambilan sampel dan pemeriksaan bakteri koliform dengan metode Most Probable Number

3) Focus Group Discussion (FGD) tentang hasil uji kual itas air dan tanggapan atau persepsimasyarakat.

FGD dilaksanakan di salah satu rumah warga yang air sumurnya tidak memenuhi Evaluasi dilakukan dengan cara mengajukan berbagai pertanyaan setelah warga mengikuti 
penyuluhan, terutama mengenai tingkat pengetahuan penduduk desa Trirenggo Bantul dalam hal standar kualitas air minum, jenisjenis penyakit infeksi yang ditularkan melalui air. Selain itu juga tindak lanjut berupa sosilalisasi dari hasil pemeriksaan laboratorium apakah sumur-sumur di desa Trirenggo, Bantul sudah mengalami pencemaran atau tidak, pasca terjadinya gempa bumi beberapa tahun yang lalu.

\section{HASIL DAN PEMBAHASAN}

Pada tahap sosialisasi yang kegiatannya berupa penyuluhan dan pembagian leaflet tentang manfaat air bersih bagi tubuh, penyakit infeksi yang ditularkan lewat air serta pengaruh kesadahan air terhadap kesehatan sangat menarik bagi para peserta. Peserta yang hadir adalah para pengurus RT setempat dan kader-kader kesehatan, ketua pemuda serta beberapa warga sekitar. Beberapa faktor yang menunjang suksesnya kegiatan ini antara lain adalah motivasi yang kuat dari ibu-ibu kader kesehatan dan pengurus RT untuk mengetahui tentang pentingnya penyediaan sumber air minum yang memenuhi standar kesehatan.

$\mathrm{H}$ asil pemeriksaan terhadap ke 100 sampel berdasarkan parameter M ikrobiologi dapat dilihat pada Tabel 1 berikut.

Tabel 1 Hasil pemeriksaan bakteri koliform pada air sumur penduduk Desa Trirenggo, Bantul

\begin{tabular}{clcc} 
No & Kualitas Air & Jumlah sumur & Prosentase \\
1 & Baik (kadar koliform maksimal 50 MPN/100 ml) & 31 & $31 \%$ \\
\hline 2 & Kurang baik ((kadar koliform total 51-100 MPN/100 ml) & 5 & $5 \%$ \\
\hline 3 & Tidak baik (kadar koliform total lebih dari $101 \mathrm{MPN} / 100 \mathrm{ml})$ & 64 & $64 \%$ \\
\hline
\end{tabular}

Dari Tabel 1 tersebut dapat diketahui bahwa 31\% sumur penduduk Pepe, Trirenggo, Bantul masuk dalam kategori baik. H anya ditemukan bakteri koliform kurang dari 50 MPN per $100 \mathrm{ml}$ sampel air.

Tabel 2 Hasil pemeriksaan bakteri Escherichia coli pada air sumur penduduk di desa Trirenggo, Bantul

\begin{tabular}{llll}
\hline No & Kualitas Air & Jumlah sumur & Prosentase \\
1 & Tidak ditemukan E coli & 3 & $3 \%$ \\
\hline 2 & Ditemukan E coli & 97 & $97 \%$ \\
\hline
\end{tabular}

Tabel 2 menunjukkan hasil pemeriksaan bakteri Escherichia coli pada air sumur penduduk di desa Trirenggo, Bantul. 97\% sumur positif terkontaminasi bakteri Escherichia coli. H anya 3 sumur saja yang tidak terkontaminasi bakteri E coli.

Berdasarkan Peraturan Menteri Kesehatan Nomor. 416/ M ENKES/ PER/IX/ 1990 


\section{5}

tentang Syarat-syarat Pengawasan Kualitas Air dan Perda N omor. 9 Tahun1995 Tentang Pengawasan Kualitas Air :

-Baik : Kadar Coliform Total maks. diperbolehkan 50 M PN / $100 \mathrm{ml}$

-Kurang baik : Kadar Coliform Total 51 - 100 M PN / 100 ml

- Tidak baik : Kadar Coliform lebih dari 101 M PN / 100 ml

Jika men gacu pada Peraturan M enteri Kesehatan tersebut, 31\% air sumur penduduk terindikasi baik dan $62 \%$ dinyatakan tidak baik karena ditemukan koliform lebih dari 101 M PN per $100 \mathrm{ml}$ sampel air. Namun jika mengacu pada hasil pemeriksaan cemaran bakteri E.coli pada air sumur, 97\% air sumur positif mengandung E.coli dan hanya 3\% air sumur saja yang memenuhi syarat layak dikonsumsi sebagai sumber air minum.

Ditinjau dari lokasi sumur di desa Trirenggo Bantul, kerapatan penduduknya sangat tinggi, jarak antara satu rumah dengan rumah yang lain sangat dekat, jarak antara pembuangan limbah rumah tangga dan septic tank dengan sumur berdekatan sehingga memungkinkan terjadinya pencemaran oleh $\mathrm{E}$. coli . $\mathrm{H}$ al ini didukung dengan banyaknya saluran septitank yang rusak akibat gempa beberapa waktu yang lalu yang belum sempat diperbaiki. Perubahan struktur tanah akibat gempa berpengaruh dengan penyebaran .

Total Coliform merupakan indikator bakteri pertama yang digunakan untuk menentukan aman tidaknya air untuk dikonsumsi. Bila koliform dalam air ditemukan dalam jumlah yang tinggi maka kemungkinan adanya bakteri patogenik seperti G iardia dan C ryptosporidium di dalamnya (Anonim, 2007). Eschericia coli adalah salah satu bakteri patogen yang tergolong koliform dan hidup secara normal di dalam kotoran manusia maupun hewan sehingga $\mathrm{E}$. coli digunakan sebagai bakteri indikator pencemaran air yang berasal dari kotoran hewan berdarah panas (Fardiaz,1992).

Pada lokasi pengambilan sampel hampir semua penduduk membuang limbah domestik dan septic tank nya dengan meresapkan ke dalam tanah sehingga air tanah mudah terkontaminasi oleh kelompok bakteri koliform. A danya bakteri pada tanah dangkal dapat disebabkan karena jarak antara septic tank dengan sumber air tanah dangkal (sumur gali) berjarak kurang dari $10 \mathrm{~m}$. Selain itu juga karena konstruksi dari sumber air tanah dangkal terdapat retakan-retakan sehingga bakter E.Colli bisa keluar dari septic tank.

$\mathrm{H}$ asil pemeriksaan kadar Kalsium dan Magnesium pada 100 sampel air sumur penduduk antara 70 - 140 ppm. Kriteria kesadahan pada air minum sebagai berikut: 1) 0-70 ppm : sangat rendah (sangat lunak), 2) 70-140 ppm : rendah (lunak), 3) 140-210 ppm : sedang, 4) 210-320 ppm : agak tinggi (agak keras), 5) 320 -530 ppm : tinggi (keras). $\mathrm{Hal}$ ini berarti bahwa air sumur penduduk $\mathrm{D}$ esa Trirenggo dalam kategori rendah. 
Sehingga di daerah tersebut semua sumber air minum masih layak untuk dikonsumsi jika dilihat dari tingkat kesadahannya.

Air sadah adalah air yang mengandung kalsium dan magnesium dengan kadar tinggi. Air sadah yang direbus akan menimbulkan endapan pada peralatan logam Air sadah tidak begitu berbahaya untuk diminum, namun dapat menyebabkan beberapa masalah. Air sadah dapat menyebabkan pengendapan mineral, yang menyumbat saluran pipa dan keran. Air sadah juga menyebabkan pemborosan sabun di rumah tangga, dan air sadah yang bercampur sabun dapat membentuk gumpalan scum yang sukar dihilangkan. U ntuk mengatasi tercemarnya bakteri E scherichia coli air sumur di D esa Trirenggo Bantul, perlunya sistem pengelolaan air limbah domestik yang baik misalnya dengan pembuatan sumur resapan dengan konstuksi sumur resapan yang baik dilengkapi dengan kerikil, pasir dan ijuk untuk memfiltrasi air buangan sehingga tidak mencemari air sumur. Pembuatan sistem konstruksi septitank yang baik seperti pembuatan septic tank dengan dua sekat sehingga air buangannya tidak mencemari air sumur. Pembuatan saluran pembuangan air yang jauh dari sumur baik sumur pribadi maupun sumur tetangga. Penggunaan air untuk keperluan memasak dan penyediaan air untuk diminum agar lebih diperhatikan (air harus benar-benar matang) agar terhindar dari penyakit diare dan penyakit lainnya yang penyebarannya lewat air

\section{SIMPULAN}

1. Air sumur gali di desa Trirenggo Bantul hanya 3\% yang layak memenuhi standar baku kualitas air.

2. Air sumur gali di desa Trirenggo Bantul tidak memenuhi standar baku kualitas air sebesar $97 \%$.

3. Air sumur gali di D esa Trirenggo Bantul sebagian besar tercemar bakteri Escherichia coli.

4. Kesadahan air sumur gali di desa Trirenggo, Bantul masih dalam ambang batas normal.

\section{UCAPAN TERIMA KASIH}

Penulis mengucapkan terima kasih kepada Direktorat Jenderal Pendidikan Tinggi D epartemen Pendidikan Nasional atas terlaksananya pengabdian ini yang telah dibiayai melalui DIPA NO MOR:0145.0/ 023-04.0/ - 2008. 


\section{DAFTAR PUSTAKA}

Anomin. 2002. Keputusan Menteri Kesehatan No.907

Tahun 2002 Tentang Persyaratan

dan Pengawasan Air

Anonim.2004. PPRI No.82 tahun 2001 Tentang Baku

Mutu Air kelas I, Kementrian

Lingkungan Hidup. J akarta.

Anonim .2004. Keputusan Menteri Negara Lingkungan Hidup Nomor: 115 Tahun 2003 Tentang Pedoman Penentuan Status Mutu Air. Menteri Negara Lingkungan Hidup. J akarta.

Bibiana, 1994, Analisis Mikroba di Laboratorium, PT.Raja Grafindo Persada, Jakarta.

Departemen Pendidikan Nasional RI, 2006, Akibat Gempa Banyak Sumur dan
Penanpung Limbah Rusak, Program Penanganan Pasca Gempa J ogyakarta, J ogyakarta.

Fardiaz, S. 1992. Polusi Air dan Udara. Kanisius. Yogyakarta.

Hadioetomo, 1988, Dasar-dasar Mikrobiologi, Bandung, Penerbit Universitas Press.

Insist, 2006, Peta Gempa Bumi J ogyakarta-J ateng, J ogyakarta.

Soemirat, 1994, Kesehatan Lingkungan, Jogyakarta, Gadjahmada University Press.

Sutrisno, T, 2004, Teknologi Penyediaan Air Bersih, J akarta, Rineka Cipta . 